\title{
ALGAZI, Gadi, GROEBNER, Valentin, JUSSEN, Bernhard, Negotiating the Gift. Pre-modern Figurations of Exchange
}

Joseph Morsel

\section{(2) OpenEdition}

\section{Journals}

Édition électronique

URL : http://journals.openedition.org/ifha/909

DOI : 10.4000/ifha.909

ISSN : 2198-8943

\section{Éditeur}

IFRA - Institut franco-allemand (sciences historiques et sociales)

Référence électronique

Joseph Morsel, « ALGAZI, Gadi, GROEBNER, Valentin, JUSSEN, Bernhard, Negotiating the Gift. Premodern Figurations of Exchange ", Revue de l'IFHA [En ligne], Date de recension, mis en ligne le 01 janvier 2004, consulté le 22 septembre 2020. URL : http://journals.openedition.org/ifha/909; DOI : https://doi.org/10.4000/ifha.909

Ce document a été généré automatiquement le 22 septembre 2020.

(CIFHA 


\title{
ALGAZI, Gadi, GROEBNER, Valentin, JUSSEN, Bernhard, Negotiating the Gift. Pre-modern Figurations of Exchange
}

\author{
Joseph Morsel
}

En décembre 1998 a eu lieu à l'Institut Historique Allemand à Paris une table ronde sur le don et la circulation des biens dans la société médiévale et à la Renaissance (avec une contribution antique). Les actes (augmentés) en sont publiés dans le volume présenté mais en traduction anglaise - pour des raisons obscures, puisque ne le justifiaient ni le lieu de la rencontre, ni l'origine des organisateurs, ni celle de la majorité des intervenants, ni les institutions finançant la rencontre, ni la collection... Cet aspect ne doit cependant pas détourner de considérer ce volume comme une contribution importante à la réflexion sur le sens social des formes de circulation des biens. Car c'est là l'élément central du volume, sur lequel insiste tout particulièrement le texte introductif : les diverses formes de circulation des biens et droits sont à considérer bien au-delà de la traditionnelle perspective matérielle (circulation de richesses quantifiables), en tant qu'actes performatifs et socialement constitutifs, à la fois réalisant et actualisant des rapports sociaux. Marcel Mauss était certes la figure tutélaire de la rencontre, mais un Marcel Mauss lui-même historicisé, dont L'Essai sur le don (1923-1924) a été utilement replacé dans son contexte historique (celui de l'identification d'une troisième voie entre l'exploitation capitaliste et l'expropriation communiste...). Certaines contributions adoptent une perspective plutôt théorique (le sens social de l'économie d'oblation dans la société médiévale et la possibilité de son appréhension à partir des modèles sociologiques ou anthropologiques) ; d'autres reviennent sur le thème du don/contre-don et le problème de la réciprocité, qui font partie des lieux communs de la médiévistique depuis quelques décennies, notamment en tant que facteurs du pouvoir seigneurial, au sein de l'aristocratie (le fief en échange $\mathrm{du}$ service) comme entre seigneurs et dépendants (les redevances en échange de la protection) ; un ensemble de contributions envisagent enfin les cas de don gratuit, 
assortis de discours qui font du don une obligation morale, qu'elle soit religieuse (don charitable) ou familiale. Quant aux modalités d'approche, elles dépendent largement des sources utilisables : pour les périodes anciennes, on a affaire à une démarche sémantique (examen du vocabulaire) ou discursive (examen des textes narratifs ou des parties narratives de chartes), tandis que celles qui concernent l'extrême fin du Moyen Âge ou les débuts de l'époque moderne procèdent à une reconstitution des pratiques sociales (notamment dans les villes). Répétons-le encore : quiconque s'intéresse au sens des pratiques de circulation des biens devrait lire soigneusement ce livre.

2 Joseph MORSEL (Université de Paris I/ Institut

3 Universitaire de France) 